\title{
INTERPRETACIONES ÍNTIMAS SOBRE LA EsCritura PERFormativa*
}

Fecha de recepción: Octubre 11 de 2013

Fecha de aprobación: Noviembre 28 de 2013

\section{Resumen}

"Interpretaciones íntimas sobre la escritura performativa" es una reflexión teórica sobre las posibles maneras de concebir la escritura creativa contemporánea; en este, la autora se refiere al texto como un espacio expandido de posibilidades creativas en donde convergen diferentes disciplinas artísticas como el teatro, el performance y la literatura. Menciona diferentes teóricos y artistas que han transformado su concepción de arte al igual que reafirma los aportes de los investigadores brasileros Christine Greiner y Pablo Assumpção quienes postulan al performance como método de investigación y la práctica y la creatividad artística como elementos vitales para consolidar la actividad teórica.

Palabras clave: escritura performativa, epistemología, creatividad, performance, desterritorialización.

\footnotetext{
* Artículo presentado como avance del proyecto de investigación creación "Desbordes: Performance, ficción, escritura", de la Maestría en Literatura UPTC, inscrito en el grupo de investigación Senderos del Lenguaje.
}

Citar: Brijaldo, G. (Enero - Junio de 2014). Interpretaciones Íntimas sobre la Escritura Performativa. La Palabra (24), 111 - 117

\section{Gina Carolina Brijaldo}

Universidad Pedagógica y

Tecnológica de Colombia ashtore@gmail.com

Licenciada en Idiomas

Modernos Español-Inglés. Docente universitaria. 


\title{
la palabra
}

\section{Intimate Interpretations About Performative WRITING}

\begin{abstract}
"Intimate interpretations about performative writing" is a theoretical reflection about the possible ways of thinking the contemporary creative writing; in this, the author refers to the text as an expanded space of creative possibilities where different artistic disciplines like theater, performance and literature converge on it. She mentions several theorists and artists who have changed her conception about art and the contributions of the Brazilian researchers, Christine Greiner and Pablo Assumpção who postulate performance as a research method and artistic practice and creativity as vital elements for consolidating the theoretical activity.
\end{abstract}

Key words: performative writing, epistemology, creativity, performance, de-territorialization.

\section{Des InTERPRÉTATIONS INTIMES SuR L’ÉCRITURE PERFORMATIVE}

\section{Résumé:}

Des interprétations intimes sur l'écriture performative est une réflexion théorique sur les possibles manières de concevoir l'écriture créative contemporaine. Ici, l'auteur fait référence au texte comme un espace élargi de possibilités créatives où convergent de différentes disciplines, telles que le théâtre, la performance et la littérature. L'auteur mentionne aussi de différents théoriciens et artistes qui ont transformé leur conception d'art, de la même manière que réaffirme les apports des chercheurs brésiliens Christine Greiner et Pablo Assumpção, qui postulent la performance en tant que méthode de recherche et la pratique et la créativité en tant que des éléments essentiels pour consolider l'activité théorique.

Mots clés: Écriture performative, épistémologie, créativité, performance, déterritorialisation. 
Escribir es dar a conocer, es seguir el bilo que se ha mantenido oculto, pero también, y sobre todo, es percibir la buella de una fisura que rompe con la noción de frontera y desdibuja el sentido dicotómico de una realidad que, imperceptiblemente, se desborda en un sinfin de pliegues. Jacques Derrida

El deseo de afrontar la escritura performativa tiene que ver con algunas preguntas ontológicas que he rastreado en ciertas obsesiones artísticas que me han acompañado desde hace varios años; entre ellas: el teatro, la literatura y el performance, disciplinas dialogantes que inevitablemente me han cuestionado como sujeto creador artístico, como lectora y escritora, y que constantemente me han confrontado conmigo misma y con la vida.

Considero necesario mencionar en esta reflexión a algunos artistas que desde mi perspectiva, se han instalado en la brecha de los discursos del arte, que han subvertido las reglas de juego a partir de continuas deconstrucciones de sí mismos y del lenguaje, de sus radicales obras artísticas; y que han reconceptualizado la noción que hasta hace poco yo tenía sobre los límites del arte. Artistas como Marina Abramovic, María Teresa Hin- capié, Sophie Calle, Rolph Abderhalden, entre otros, han erigido subjetividades desbordadas en pre-escrituras, escrituras y post-escrituras. Estos "cuerpos vibrátiles" en términos de Suely Rolnik inauguran lenguajes performados, indiscutiblemente vivos y sanguíneos; nos muestran sus poéticas íntimas expuestas en teatros, galerías de arte o espacios no convencionales, han hecho de sus cuerpos su obra plástica intervenida con experiencias de vida.

Al abordar el concepto de performance (vertiente que nutre el concepto y práctica de la escritura performativa). Renato Cohen desglosa de manera más concreta la concepción ontológica a la cual es necesario referirse.

\section{A performance está ontológi- camente ligada a um movi- miento maior, uma maneira de se encarar a arte; A live art. A live art é a arte ao vivo e também a arte viva. É uma forma de se ver arte em que se procura uma aproximaçâo directa com a vida, em que se estimula o espontâneo, o natural, em detrimento do elaborado, do ensaiado ${ }^{1}$ (Cohen, 2011, p. 38).}

Conviene traer a colación la concepción de escritura performativa como postura epistemológica, porque abre el campo de posibilidades teóricas y creativas, y afirma un espacio para poner en juego saberes interdisciplinares. Esta idea ya ha sido explorada por varios investigadores de la escena artística; entre ellos, los brasileros Christine Greiner y Pablo Assumpção. Greiner, como profesora del Departamento de Lenguajes del Cuerpo, y Assumpção, como artista de performance/ video, dramaturgo y también como docente en el Instituto de Cultura e Arte, han enfocado sus investigaciones hacia un entendimiento del performance como conocimiento corporal:

generar una discusión sobre el concepto de performance como episteme y crear un espacio para la experimentación artística como método de investigación teórica. El entendimiento del performance como episteme - como "un modo de conocer" la realidad - obliga a cuestionar la misma naturaleza del conocimiento y de la investigación, y sugiere que la práctica y la creatividad artísticas son operadores centrales en la llamada actividad teórica (Assumpçao, 2008).

Entender la postura de estos dos investigadores brasileros permite enriquecer y ampliar el concepto que podamos cons-

1 El performance está ontológicamente conectado a un movimiento mayor, una manera de ver el arte; Un live art. Un live art es el arte en vivo y también el arte vivo. Es una forma de ver arte en el que se procura una aproximación directa con la vida, en que se estimula lo espontáneo, lo natural, en detrimento de lo elaborado, lo ensayado. 
truir sobre la escritura performativa. Por tanto, es válido afirmar que esta, es ante todo una práctica del cuerpo y que es con este que se conoce la realidad de la cual se escribe, es decir, que es en la experiencia donde esta escritura acontece, en tanto que la teoría se va reconstruyendo, replanteando simultáneamente. Escribir performativamente también significa entender que la teoría es cambiante, dinámica, que se mueve al ritmo de los dispositivos performáticos que vamos hallando.

En el capítulo 7 "Performative Language" (Lenguaje Performativo) del libro Literary Theory, (Teoría Literaria), Jonathan Culler aborda el concepto de lenguaje performativo como problema dentro del "reino de la teoría" pero obviamente va más allá: “The problem of 'performative' language brings into focus important issues concerning meaning and effects of language and leads to questions about identity and the nature of the subject"'2 (Culler, 1997, p. 94).

Como creadora y estudiante de una maestría en Literatura, revivir la experiencia de la escritura creativa me asusta. It freaks me out! Quizá porque siempre ha significado una descarga emocional de alto voltaje que ha desembocado en la pregunta por la identidad como bien lo ha planteado Culler, o en cuestionar el concepto de autor (Foucault, Barthes) así como la sensación corporal de vacío y pérdida. Pero más allá de eso, lo que me hace seguir explorando el campo de la escritura, entre otras cosas, es el deseo de incorporar (al igual que muchos artistas que admiro) otros discursos y disciplinas y sus cuestionamientos a mis propios procesos de creación.

Estar expuesta, ser atravesada por otras voces y prácticas artísticas eleva mi experiencia en el arte a un nivel exponencial. Y considero que de eso se trata la escritura performativa, de instalar al cuerpo en un espacio de salpicaduras, de giros inesperados, de saltos al vacío, de choques de subjetividades, de encuentros y desencuentros con el otro, con las palabras, vivir en abruptos pero exquisitos descubrimientos inmersos en la vorágine del lenguaje. Hallo gran similitud entre lo que concibo como escritura performativa y lo que Adriano Spatola denominó "poesía plena": busca hacerse un médium total, superar cualquier limitación, englobar música, pintura, arte tipográfico y cualquier otro aspecto de la cultura, con la aspiración utopística de volver a los orígenes" (citado por García y Millán, 1975, p. 16).

Quizá por esto mismo, le he seguido el rastro a Adriana María Urrea en la reflexión teórica "Experimentum Vitae", que forma parte de uno de los cuadernillos publicados por la Maestría Interdisciplinar en Teatro y Artes Vivas de la Universidad Nacional de Colombia; en esta, la filósofa nos habla de la manera como el laboratorio de creación-investigación impactó en el colectivo de maestros y estudiantes:

En el laboratorio se dispersaron y concentraron nuevos saberes y preguntas; soledades y colectivos. Hubo explosiones e implosiones. Aparecieron voces nunca oídas. Cuerpos nunca sentidos. Discusiones y búsquedas sobre el neutro, la presentación y la representación, el performance, la corporeidad, el sonido, la voz, lo relacional, el gesto, las técnicas. Nuestros corpus teóricos y nuestros cuerpos orgánicos fueron expuestos al máximo de vitalidad, vibratilidad, voltaje y reverberación (Urrea, 2010, p. 60).

En concordancia con esta perspectiva, y cartografiando otro territorio bastante cercano a la escritura performativa, está

2 El problema del lenguaje "performativo" pone de relieve cuestiones de significado y efectos del lenguaje y lleva a preguntarse por la identidad y la naturaleza del sujeto. 
lo que lúcidamente Nicolas Bourriaud denominó: "relacional", término que aborda en su libro Estética relacional, en donde analiza el trabajo de algunos importantes artistas de los años noventa. Pero, ¿de qué manera, este crítico de arte me ha dado luces en mi búsqueda? Pues bien, reitero la afirmación de que la escritura performativa puede ser un campo de experimentación colectiva, al igual que un territorio de posibilidades, de relaciones y conexiones de intersubjetividades, donde la búsqueda de nuevas maneras de expresión se superpone a la hoy en día cuestionada idea romántica del gran genio creador exiliado, construyendo "la gran obra".

La posibilidad de un arte relacional - un arte que tomaría como horizonte teórico la esfera de las interacciones humanas y su contexto social, más que la afirmación de un espacio simbólico autónomo y privado- da cuenta de un cambio radical de los objetivos estéticos, culturales y políticos puestos en juego por el arte moderno (Bourriaud, 2008, p. 13). Lo que se derrumba delante de nosotros es sólo esa concepción falsamente aristocrática de la disposición de las obras de arte, ligada al sentimiento de querer conquistar un territorio. Dicho de otra manera, no se puede considerar a la obra contemporánea como un espa- cio por recorrer (donde el "visitante" es un coleccionista). La obra se presenta ahora como una duración por experimentar, como una apertura posible hacia un intercambio ilimitado (Bourriaud, 2008, p. 14).

Lo importante de esta cita es que reflexiona acerca de uno de los propósitos del arte contemporáneo (aquí posiciono el concepto de escritura performativa como manifestación artística) y es el de la "desterritorialización”, expresión estudiada en diversas teorías artísticas. Y una vez más nos hablan de la experimentación colectiva como construcción del sentido de la obra. En términos de imaginar cómo podría ser una escritura que tenga las características de la escritura performativa, podríamos remitirnos a Rayuela de Julio Cortázar, novela que con un lenguaje audaz explora los territorios del surrealismo, donde el juego de múltiples lecturas se convierte ya en un hecho performativo, así como el de la puesta en escena de elementos como: ruptura del lenguaje y reglas gramaticales, construcción de nuevos códigos de interpretación de la realidad y la fantasía, y el de hacer copartícipe al lector, que, en términos de Bourriaud, ya no es un "visitante", sino un lector emancipado, constructor de sentido(s) de la obra.
A propósito del surrealismo, cabe ampliar un poco en cómo en este movimiento literario se dan prácticas de escritura performativa:

$\mathrm{Na}$ literatura, podem se mencionar tanto experiências empíricas, como a proposta surrealista da escrita automática, em que vale o jorro, o fluxo e nâo a construçâo formal, quanto experiências altamente elaboradas, como as de James Joyce que em Ulisses, por exemplo, procura reproduzir o fluxo vital da emoçâo e do pensamento e narra a epopéia de umcidadâo absolutamente comum $^{3}$ (Cohen, 2011, p. 39)

La escritura performativa hecha por los surrealistas tiene el carácter de entropía mencionado por Cohen, en otras palabras, un alto grado de libertad y capacidad creadora. Performar es realizar. En How to do things with words, (Cómo hacer cosas con palabras), escrito por J. L. Austin, encontramos que este filósofo nos plantea dos tipos de enunciados: "constative utterances" (enunciados constatativos) y "performative utterances" (enunciados realizativos).

La palabra "realizativo" será usada en muchas formas y construcciones conectadas entre sí, tal como ocurre con el término "imperativo". Deriva, por supuesto, de "realizar", que es el ver-

3 En la literatura, podemos mencionar tanto experiencias empíricas, como la propuesta surrealista de una escritura automática, donde vale más la corriente o flujo de conciencia quela construcción formal, esto se puede ver en experiencias altamente elaboradas como la de James Joyce en Ulises, por ejemplo, en la que intenta reproducir el flujo vital de las emociones y del pensamiento y narra la epopeya de un ciudadano absolutamente común. 
bo usual que se antepone al sustantivo "acción”. Indica que emitir la expresión es realizar una acción y que ésta no se concibe normalmente como el mero decir algo (Austin, 1998, p. 6).

La expresión lingüística "realizativa" que posteriormente fue denominada "performativa" se entiende como "aquella expresión lingüística que no consiste, o no consiste meramente, en decir sino en hacerlo" (Austin, 1998, p. 18). La lupa de Austin en la escritura performativa se enfoca hacia cómo comprendemos el lenguaje, concretamos los actos comunicativos $\mathrm{y}$ ponemos en juego nuestras visiones de mundo.

En concordancia, Jonathan Culler nos recuerda: "Decir: "prometo pagarte" no es describir un estado de asuntos sino performar el acto de la promesa; el enunciado es por sí mismo el acto" (1997, p. 94). El propósito de mi búsqueda con la escritura performativa, ha sido el de "hacer" más que "decir".

Hubiese querido un diván forrado de una fina tela rojo carmesí, un psicoanalista de piernas cruzadas, traje clásico y oscuro. Un reloj antiguo de madera colgado en la pared blanca; y una gran ventana sin rejas para que su claustrofobia cada vez más aguda lo perciba al instante. La huida por si llegase a quedar encerrada en las palabras.

La chica exploradora que nunca ha conocido el Amazonas encontró un resguardo agreste para escribir. El paisaje nunca fue tan hostil, tan delirante. Un lugar inmaculado. Trapeado y encerado. Un pequeño apartamento antiguo donde la acumuladora de rostros dibujados en el techo tendrá que escribirse a sí misma para construir esta historia. Se diluye en largos periodos de silencio, en visitas imaginadas al psiquiatra y en escenarios jocosos y fúnebres asesinando a Lady Macbeth. ¿Qué cuerpos habitan los espacios? ¿Qué prácticas de vida/muerte/arte pueden pensarse?

Lady Macbeth tiñe su cabello canoso con tintura barata. La verdad es que sin la existencia de esta dama, no existiría el juego. La búsqueda sería aburrida. El éxito de la trama estará en la capacidad que nuestra exploradora posea para respirar bajo el agua. El territorio de lo íntimo poco a poco será abruptamente penetrado. Los jinetes de la reina destruirán todo a su paso. Despojarán a la chica exploradora de su casco y sus binóculos, de sus botas y su soga para saltar abismos. Cuerpo- expuesto. Desnudo. Ocupando un campo minado. Paradójicamente un territorio que ya no le pertenece, un espacio ajeno. Su lugar de batalla no podría ser más encantador y sórdido. Ella se ha instalado en los aposentos de la reina. Nuestra exploradora deviene en constantes preguntas donde escribir desde un lugar propio se ha convertido en habitar zonas limítrofes.

Un no-territorio para crear. Entonces, se hace más latente la idea de la escritura como intervención de escenarios estáticos, de desterritorialización donde la acción acontece. Acción. Todo lo demás son simples decorados para nuestra chica exploradora quien ha estado rondando estos terrenos movedizos.

"The literary utterance too creates the state of affairs to which it refers, in several respects. First and most simply, it brings into being characters and their actions"4 (Culler, 1997, p. 96).

Como lectora también he podido performarme, interviniendo escenarios, deconstruyendo situaciones y plantearme caminos alternos de interpretación, creando nuevas realidades a través de la ficción. $\mathrm{Al}$ pensar en lo que podría ser una segunda parte de este artí-

4 El enunciado literario también crea un estado de relaciones a las cuales se refiere en muchos aspectos. El primero y más sencillo, el de dar existencia los personajes y sus acciones. 
culo, me aventuraría a ahondar en lo que Barthes denominó "La muerte del autor": "al señalar la muerte del autor y el nacimiento del lector, Barthes revela una característica más de lo performativo: lo que las palabras hacen es producir una subjetividad, es decir, una forma concreta de ser consciente y de entender el mundo" (Centre de Creació del Cos I el Moviment, 2012). Así pues, queda abierto el diálogo con los trapecistas de la escritura, con aquellos que fueron capaces de saltar al vacío y han descendido en los borrosos límites del arte y la vida.

\section{Referencias}

Assumpçao, C. G. (2008). Mesa de trabajo: Performance como método de investigación. Recuperado de www.hemisphericinstitute.org/esp/.../colombia_workgroup_16.html

Austin, J. (1998). Cómo hacer cosas con las palabras. Barcelona: Paidós.

Bourriaud, N. (2008). Estética relacional. Buenos Aires: Adriana Hidalgo.

Cohen, R. (2011). Performance como linguagem. Sao Paulo: Perspectiva.

Centre de Creació del Cos I el Moviment. (2012). Glosario 03 Performatividad (según John L. Austen y Roland Barthes). Recuperado de http://granerbcn.cat/tag/performatividad/

Culler, J. (1997). Literary Theory. A very short introduction. New York: Oxford University Press.

García, F. M. (1975). La escritura en libertad. En F. M. García, La escritura en libertad (pp.331 - ¿?????)Falta una página Madrid: Alianza.

Urrea, A. M. (2010). Experimentum vitae. Bogotá: Maestría Interdisciplinar en Teatro y Artes Vivas. 